\title{
Perceived Experiences of Patients With Breast Cancer: a Qualitative Study of the Influence of Spirituality and Health Beliefs Among Preoperative Breast Cancer Patients in Ghana
}

\author{
Victoria Akuorkor Acquaye \\ University of Cape Coast \\ Alfred Dickson Dai-Kosi ( $\nabla$ daikosi@yahoo.com ) \\ University of Ghana \\ Kingsley Kwadwo Asare Pereko \\ University of Cape Coast \\ Christian Ackom \\ University of Cape Coast
}

\section{Research Article}

Keywords: Spirituality, coping, health beliefs, breast cancer, depression, anxiety and Ghana

Posted Date: February 2nd, 2022

DOI: https://doi.org/10.21203/rs.3.rs-1314827/v1

License: (c) (1) This work is licensed under a Creative Commons Attribution 4.0 International License.

Read Full License 


\section{Abstract}

Background: Cancer is a major threat to public health globally and in Ghana. Breast cancer is a serious health problem among women which affects the daily functioning of the individual and their psychological health.

Aim: The study examined the influence of spirituality and health beliefs on anxiety and depression among preoperative breast cancer patients in Ghana.

Methodology: This is a qualitative study involving 54 preoperative breast cancer patients selected from 3 referral hospitals in Accra namely: 37 Military hospital, Korle Bu Teaching Hospital, and the Sweden Ghana Medical Centre all in Ghana. The study collected data via one-on-one in-depth interviews (IDI) and Focus group discussion (FGD).

Result: Thematic analysis was done and the results revealed spirituality and health beliefs influenced patients' perception and health-seeking, while spirituality in particular helped patients cope with the disease. Participants felt that breast cancer treatment which is mainly through surgery increased their anxiety levels.

Discussion: This study generates knowledge about the relations between spirituality, health beliefs and psychological wellbeing among breast cancer patients in Ghana. The study implies that spirituality and health beliefs of the cancer experience have implications for psychological wellbeing.

\section{Background}

The threat of breast cancer has become more imminent as globally, about $25 \%$ and $15 \%$ of all new cancer cases and cancer deaths respectively among females were due to breast cancer [1]. Africa currently has the highest age-standardized breast cancer mortality rate worldwide, with the highest incidence rates being recorded within the sub-Saharan African sub-region [1]. The rise in breast cancer burden in part is associated with the aging global population, obesity, tobacco use, environmental pollution and dietary choices [2]. In 2020, there were 2.3 million women diagnosed with breast cancer and 685,000 deaths globally [3]. In Ghana, Clegg-Lamptey and Vanderpuye [4] stated that about $16 \%$ of all cancers from the pathology records of Korle Bu Teaching hospital are established to be breast cancer and it is the most widespread among women. In Africa, the likely factors leading to the rise in breast cancer deaths include barriers to access appropriate treatment, poor health care schemes, lack of detection devices and alternative health beliefs [5].

Patients with breast cancer experience depression and anxiety and general psychological distress perhaps as a result of some of the challenges associated with breast cancer treatment including unpleasant side effects, physical pain, changes in physical appearance, loss of self-esteem, recurrence, social disorientation and financial difficulties [6]. The implications of these factors may result in decreased quality of life among patients with breast cancer. 
A large number of adult patients undergoing breast cancer surgery have high levels of anxiety such as increased tension, nervousness, apprehension and aggression including other forms of distress before surgery $[7,8]$.

Studies have given the various reasons for the cause of presurgical anxiety. The preoperative anxiety may arise due to pain, anaesthesia, unsuccessful surgery, loss of individual identity, recuperation around unknown people, loss of control, failed recovery and death [8].

Katz and Hawley [9] indicated that some qualitative studies have identified cultural values as significant variables in the treatment preferences of individuals with strong spiritual beliefs that breast cancer diagnosis and outcome are under God's control.

There is paucity of research into spirituality and health beliefs in relation to anxiety and depression among preoperative breast cancer patients from patients perspective and that is what this qualitative study investigated.

\section{Materials And Methods}

This is a qualitative study involving 54 preoperative breast cancer patients selected from 3 referral hospitals in Accra namely: 37 Military hospital, Korle Bu Teaching Hospital, and the Sweden Ghana Medical Centre all in Ghana. The study collected data via one-on-one in-depth interviews (IDI) and Focus group discussion (FGD). The Korle-Bu Teaching Hospital and the 37 Military hospitals are tertiary hospitals in Ghana, which are the major referral centres located in the southern zone of the country. The Sweden Ghana Medical Centre also situated in Accra is the only private Oncology clinic in Ghana and as such draws its clients from a diverse population especially those seeking private care.

Ethical approval was obtained from the Noguchi Memorial Institute for Medical Research, Accra and clearance was also obtained from the Institutional Review Boards of the Korle-Bu Teaching hospital and the other hospitals involved in the study.

A sample of 54 patients with breast cancer awaiting surgery was selected using purposive and convenience sampling techniques for both one-on-one in-depth interviews (IDI) and focus group discussion (FGD). The one-on-one in-depth interviews (IDI) engaged 10 participants each from the 3 health facilities making a total of 30 while additional 8 patients were selected from each of the 3 hospitals totalling 24 participants in the focus group. Data were collected through interviews lasting approximately between 30 mins to one hour per session. Pseudonyms were given to all participants to protect their anonymity. Each participant was interviewed just once.

The interview instruments were developed by the researcher, pretested, and revised in order to facilitate maximum understanding of all patients. All interviews were conducted in a dedicated doctors' consulting rooms by 3 trained field assistants who had a 2-day training and rehearsal led by the researcher. All 
interviewers held a pre-test interview sessions that were evaluated and discussed with the team in order to ensure consistency among interviewers and effective data collection.

Preoperative women diagnosed with stage I, II and III type of breast cancer without any cognitive impairments were qualified to participate in the study while those with terminal cancer (Stage IV) and any cognitive impairments were excluded from the study.

Thematic analysis was used to analyze both the one-on-one interviews and the Focus group discussion. It was analyzed using narrations and presentations from the point of view of the participants using the six phases proposed by Braun and Clarke [10].

\section{Results}

The One-on-one in-depth interview covered 30 participants. Their ages ranged from $30-59$ with a mean age of 46.47. Five participants did not have any formal education, 9 had basic education, 14 had been to second cycle institutions and 2 were first degree holders. Twenty subjects were married, 7 Divorced and 3 were single. The demographic characteristics of the One -on- one interview for breast cancer participants is presented on Table 1 
Table 1

Demographic Characteristics of One -on- one interview Participants

\begin{tabular}{|c|c|c|c|}
\hline Code & Age & Educational Level & Marital Status \\
\hline 1 & 50 & Secondary Education & Married \\
\hline 2 & 52 & Primary/Middle/ JSS/JHS & Married \\
\hline 3 & 51 & No formal Education & Married \\
\hline 4 & 53 & Secondary Education & Single \\
\hline 5 & 30 & Secondary Education & Single \\
\hline 6 & 40 & Primary/Middle/ JSS/JHS & Married \\
\hline 7 & 41 & Primary/Middle/ JSS/JHS & Married \\
\hline 8 & 31 & Primary/Middle/ JSS/JHS & Married \\
\hline 9 & 54 & Secondary Education & Widowed \\
\hline 10 & 55 & Primary/Middle/ JSS/JHS & Divorced \\
\hline 11 & 42 & Primary/Middle/ JSS/JHS & Divorced \\
\hline 12 & 56 & First Degree & Married \\
\hline 13 & 57 & First Degree & Married \\
\hline 14 & 32 & Secondary Education & Divorced \\
\hline 15 & 33 & Secondary Education & Divorced \\
\hline 16 & 43 & Secondary Education & Married \\
\hline 17 & 56 & Secondary Education & Married \\
\hline 18 & 43 & Secondary Education & Divorced \\
\hline 19 & 57 & Secondary Education & Single \\
\hline 20 & 44 & Secondary Education & Married \\
\hline 21 & 58 & No formal Education & Married \\
\hline 22 & 59 & Secondary Education & Divorced \\
\hline 23 & 50 & Secondary Education & Divorced \\
\hline 24 & 35 & Primary/Middle/ JSS/JHS & Married \\
\hline 25 & 36 & Primary/Middle/ JSS/JHS & Married \\
\hline 26 & 51 & No formal Education & Married \\
\hline
\end{tabular}

Secondary Education: SSS/SHS/ 'A' Level/ 'O' level /Vocational school 


\begin{tabular}{|llll|}
\hline Code & Age & Educational Level & Marital Status \\
\hline 27 & 37 & Primary/Middle/ JSS/JHS & Married \\
\hline 28 & 45 & Secondary Education & Married \\
29 & 51 & No formal Education & Married \\
30 & 52 & No formal Education & Married \\
\hline \multicolumn{4}{l}{ Secondary Education: SSS/SHS/ 'A' Level/ 'O' level / Vocational school } \\
\hline
\end{tabular}

There were 24 participants in the Focus group discussion, ages ranged from 20 - 55 years with a mean age of 44.8. Two participants had post graduate degrees, 4 had no formal education, 3 participants had basic education, 7 had secondary education and 8 had first degree. 14 patients were married, 2 Divorced and 8 single. The demographic characteristics of the Focus group participants is presented on Table 2 
Table 2

Demographic Characteristics of Participants in the Focus group discussion.

\begin{tabular}{|c|c|c|c|}
\hline Code & Age & Educational level & Marital Status \\
\hline 1 & 53 & First Degree & Married \\
\hline 2 & 46 & Post Graduate & Married \\
\hline 3 & 52 & No Formal Education & Single \\
\hline 4 & 48 & Secondary Education & Married \\
\hline 5 & 55 & First Degree & Married \\
\hline 6 & 20 & Primary/Middle/ JSS/JHS & Married \\
\hline 7 & 54 & No formal Education & Married \\
\hline 8 & 40 & First Degree & Married \\
\hline 9 & 38 & Secondary Education & Divorced \\
\hline 10 & 22 & Secondary Education & Single \\
\hline 11 & 41 & Secondary Education & Married \\
\hline 12 & 42 & Secondary Education & Single \\
\hline 13 & 43 & Secondary Education & Single \\
\hline 14 & 36 & First Degree & Married \\
\hline 15 & 49 & First Degree & Married \\
\hline 16 & 53 & First Degree & Married \\
\hline 17 & 48 & First Degree & Married \\
\hline 18 & 46 & First Degree & Married \\
\hline 19 & 47 & Primary/Middle/ JSS/JHS & Married \\
\hline 20 & 51 & No formal Education & Single \\
\hline 21 & 43 & Secondary Education & Single \\
\hline 22 & 51 & Post Graduate & Divorced \\
\hline 23 & 45 & Primary Education & Single \\
\hline 24 & 53 & No formal Education & Single \\
\hline
\end{tabular}


Each of the themes that emerged from the study with their corresponding sub themes is presented in Table 3.

Table 3

Themes developed from the data analysis.

\begin{tabular}{|ll|}
\hline Themes & Sub themes \\
\hline Perceived cause of Breast cancer & $\begin{array}{l}\text { (Traditional beliefs Versus Medical ) } \\
\text { Spiritual or evil attack }\end{array}$ \\
\hline Hereditary/ Biogenic factors \\
\hline Emotional issues & Apprehension of recurrence \\
\hline & Body image \\
\hline Sreatment & Stigmatization \\
\hline Spirituality & Support of family and friends \\
\hline & Surgery \\
\hline
\end{tabular}

The results for both the One-on-one interviews and Focus group discussion are presented according to the emerging themes from the study.

\section{Perceived cause of breast cancer}

Participants had varied perception about the cause of breast cancer, while majority thought it was due to evil attack others attributed it to medical factors.

\section{Evil Attack}

Most of the respondents interviewed concluded that their breast cancer was caused by some form of spiritual or evil attack. The greater majority of breast cancer patients in both IDI and FGD thought that because they had led decent lives the only plausible reason for the condition might be spiritual or evil attack and that they did not anticipate such conditions to plague them. This was illustrated in a response to an interview question on: "What do you think is the cause of your disease"?

"Errrr there is nothing more than spiritual attack or what do you think?

A follow up question on why the thought about evil attack also yielded the response: "Look hmmmmmmm. I have tried to live a very decent life throughout my entire 44 years only to 
face this type of disease? I feel sad about this whole issue; this is basically the work of the devil since it doesn't like any good thing."

Similar responses to the same question as to the cause of the disease were recorded with the FGD and an illustration follows:

"My opinion is that this disease cannot be from the Lord or normal sickness"

Why do you think so?"Because no member of my family has experienced this before. Do you see what I'm saying? No one from my family ever had it then it should be from the enemy emmmm..... mean the evil spirit or what errrr.... What is your view?"

\section{Medical (Heredity/biogenic)}

On the medical causative theme, significant minority of the respondents however indicated that they thought that the condition was as a result of biogenic or hereditary cause. An interviewee's narration is presented as:

"You mean what I think as the cause how can I tell specifically my sister? I thought I have lived a good life right from my childhood years but hmmmmm .....sobs ..... what I can say is that, you know, my sister had the same condition so I 'm tempted to conclude that it was caused by heredity.."

Another young lady in the FGD puts it this way:

"On what causes breast cancer I can only say that maybe because I haven't given birth before and I'm already 37 years old. Hmmm Awwww [shakes head in very sad state]."

\section{Emotional Impact of Breast Cancer}

This theme explored the emotional experiences preoperative breast cancer patients go through. The subthemes that emerged indicated that majority of them were anxious about their condition, some due to their fear of recurrence, body image and stigmatization.

\section{Recurrence}

Issues of recurrence were a worry to majority of participants. A 40 year old woman expressed her views during the IDI in the following words: What are your worries about your disease?

"My main worry is what happens after the operation. Will I be free or the disease will recur? I don't want to go through surgery again."

A similar response in the $F G D$ is: 
"My sister for me the main thing that makes me worry so much is the fact that after the surgery, some tend to recur.

Why is that your most concern? "The doctors give you all the assurances and you go and later the disease don't leave you". Body image was also a major concern to the patients. Participants were worried about how their breasts will look like after the surgery. Their responses are presented in the following narrations:

"Eeiiiih the fact that I will have to move without one breast makes me very sad. Hmmmmm no matter whatever anyone says, you can't convince me that l'll be the same person again after the surgery."

Another narration from a patient from FGD on body image is presented below:

"I've grown lean, I feel shy when I go out so these days I don't go out, I don't attend funerals and other social gatherings. People see me and ask if I I am sick because of how lean I've grown now"

\section{Stigmatization}

The narration of a lady is summed up in the following way:

"I feel very lonely and have no one to confide in with my troubles." Why? "Most people look at you someway and even friends don't want you around now"

On the issue of Social support a lot of interesting views were expressed by the respondents the notable ones are captured here: Do you get social support?

A participant, during the interview responded in affirmative; "Yes" and to a follow up question of which form? This is what she has to say:

"You see errrh..... My family helps in a good measure. I also have one good friend who has been supportive, my pastor also prays for me and the church has contributed money towards my surgery. My church members come home to pay me visit and to pray for me."

\section{Treatment (Surgery)}

To the question what do you think about the impending surgery? The following narrations from both IDI and FGD follow:

"Madam Hmmm ........., Yeah you see, if I say that the disease and the impending surgery are not causing me sleepless nights, I 'm not telling the truth. Errrr.... I'm afraid about it"

Why do you look so worried about the surgery? "I hear some people they do it for them and it comes back or even die, how is mine going to be, I can't tell, only God can save me. I'm really scared and worried about the situation." 
A 22 year participant expressed her worry and about the surgery in the following extract

"It's difficult to think about what is going to happen to you during such a surgical procedure. I haven't had surgery before so I'm scared that the operation will result in me getting a sore which will be difficult to treat. Hmmm .... You see, whenever I get a sore, it takes time for it to heal. I'm also getting very worried about my breast."

The impending surgery and its outcome were cited as contributing to the anxiety and depression among the participants.

\section{Spirituality}

The role of spirituality was significant, majority of the breast cancer patients in both groups expressed high hopes that God or Allah was their refuge that they had and by Him all things are possible. The results are presented in the following extracts: A young trader (33 years) put it in the following terms:

"I believe that my sickness will heal very soon, I mean very very soon because I know that God will see me through. At first I was afraid that I will die like other women I've heard of but now I trust God to help me."

The optimism of a 51 year old lady was put it in the following terms:

"I know that God will never let me down because I try to worship him in all sincerity and Also God is the final healer and therefore whatever the doctors are going to do will only be physical manifestation of God's initial work on how I should be healed."

This 54 year old lady was not too sure about when to recover but believes in the power of prayer so that God can heal her as illustrated below:

"I pray a lot. God is in control. You see my sister...... anytime I'm in pains and discomfort and pray to God, he hears and the situation improves."

Notwithstanding the fact that majority of the women indicated that prayer and God factor play significant roles in coping with the illness, small minority of them were not certain about how to cope and were quiet indifferent or hopeless under the circumstance as presented from IDI and FGD as follows:

"Hmmmm ..... about recovering? I don't really know, I think of it but can't say. I live each day wondering what happens next because this disease has killed a number of women I have heard of so what will happen to me I don't know".

"For me I am going through the treatment and hoping that the doctors are able to save me and others in the same situation but / can't......."

\section{Discussion}


This qualitative study reveals that spirituality greatly influences patient's conceptualization of diseases and major health decisions. A Significant number of patients with breast cancer attributed the cause of their disease as evil attack or the enemy. To many Ghanaians their interpretation of illness is different from the Westernized world probably due primarily to cultural factors. This is probably due to the African's belief and perception of diseases being influenced by cultural factors [11]. These cultural interpretations may have resulted in women seeking health care elsewhere instead of the health facilities. The results indicated that majority of breast cancer patients attributed the cause of the illness to superstitious beliefs. Some of the reasons given included evil attack, devil, from the enemy and some through dreams they had. This is in line with the assertion by Mbiti [12] that in Africa people assign different forms of interpretations to diseases they consider as strange. There was however a minority of patients who indicated that they believed their conditions were brought about as a result of biological or hereditary factors. Some of the women also attributed their health condition to the fact that they did not have children. Others attributed it to familial factors. This is in line with what Parkinson's [13] gave as risk factors of breast cancer, which included personal/family history of breast cancer, and nulliparity. Those who thought their illness had medical basis would access medical care quickly. In this study where the majority attributed the illness to superstitious beliefs then it stands to reason that they could be anxious and depressed as issues related to superstition to Ghanaians are negative.

In Ghana, some patients with breast cancer report late for medical attention [4]. The most worrying aspect is that even after reporting late to the health facilities, a lot of patients abscond when treatment had started and some of the absconders afterward went back to the hospitals when the disease had reached an advanced stage and as such became untreatable. Studies have pointed out optimistically that breast cancer could be treated successfully if patients report early to the hospitals for diagnosis and treatment [14]. In this case, the situation gets compounded if the individual patient has health belief that consistently appraises the cause of the illness as spiritual or evil attack, then the chances of such a patient visiting the hospital would be very limited. Lack of education on breast cancer was most probably the reason why the participants gave the superstitious reasons for the aetiology of breast cancer.

The issue of possible recurrence of the disease, the idea of putting pressure on the family and body image featured prominently in the emotional impact of breast cancer. Other emotional impact issues were concerns about stigmatization, concerns about children and whether participants had social support or not.

Some were also of the view that their anxiety was due to their concerns about recurrence and about children in case of death. This is in line with a qualitative study by Fang, Shu and Corso [15] which examined the experiences of Taiwanese women who underwent mastectomy. The findings in that study showed that majority of the women were very concerned about their ability to play their societal role as women, including their ability to bear children. The reasons given by participants for their anxiety in this study are understandable. 
Stigmatization, unpleasant side effects, physical pain, changes in physical appearance, and loss of selfesteem are some of the factors leading to depression among breast cancer patients. Participants in this study had body image issues and stigmatization leading to depression. This is consistent with the findings of [16] who gave among other factors body image and stigmatization as causes of depression in breast cancer patients. Sheldon [17] maintains that not only do physically attractive persons have advantages in their social worlds, but having the belief that one is attractive also fosters social confidence and general feelings.

The side effects of chemotherapy like hair loss, weight loss or gain can affect how these patients view themselves. If they did not welcome such changes then they were likely to be depressed. Body image significantly influences behaviour: An individual's conscious and unconscious body image influences behaviour, particularly interpersonal relationships [18]. Watson and his colleagues [19] identified helplessness and hopelessness as correlates to the risk of recurrence of breast cancer.

Majority of the breast cancer patients were of the view that they enjoyed a lot of support from the family and even friends. Those who indicated they did not benefit from social support were less cheerful as seen in their narrations. This is evidenced in studies that reported that social support is beneficial to the physical and mental health of breast cancer patients [20]. Further, it is common for breast cancer patients' friends and family to withdraw out of fear and awkwardness at a time when these women need their support the most [21].

It is not surprising that majority of the participants indicated they were anxious about the surgery because a number of studies have pointed to that fact. Pritchard [8] stated that just the mere information that an individual is to be scheduled for surgery can lead to increased anxiety in many patients. Body image issues, financial, stigmatization and change of roles were among the factors that affected anxiety and depression among participants. Social support helped participants cope with the psychological problems.

The effect of spirituality on coping with anxiety and depression was seen in this study. In this study, a large majority of the participants said they used spirituality to cope with the illness and the anxiety and depression associated with their impending surgery. The fact that some reported that God is responsible for their treatment, the doctor being God's instrument in their treatment, and the fact that almost all said they prayed were indicative of the strong spirituality with coping. This is consistent with [9] findings which indicated that some qualitative studies have identified cultural values as significant variables in the treatment preferences of individuals with strong spiritual beliefs that breast cancer diagnosis and outcome are under God's control.

In conclusion, anxiety and depression were expressed by patients as some challenges they faced. Some of them seem to be ignorant of the challenges brought by the disease. Spirituality played a major role in the participants coping with the disease while health belief also largely determine their health decisions. Spirituality is a major factor to consider in helping pre surgical patients cope with psychological problems especially anxiety and depression

Page 13/16 


\section{Declarations}

\section{Acknowledgement}

The authors are thankful to officials of the three medical facilities for the immense support during data collection.

\section{Competing interests}

The authors have no conflict of interest to declare.

\section{Funding}

No funding was received and hence it was financed by the authors.

\section{Declaration}

Ethical approval was obtained from the Noguchi Memorial Institute for Medical Research, University of University of Ghana, Accra and clearance was also obtained from the Institutional Review Boards of the Korle-Bu Teaching hospital and the other hospitals involved in the study.

\section{Data Availability statement}

The qualitative data generated and used for analyses in the current study are available from the corresponding author on reasonable request.

\section{Informed consent}

All participants had signed a written informed consent prior to their participation in the study. In terms of publication, no pictures or images of participants were included in the study.

\section{References}

1. Azubuike, S. O., Muirhead, C., Hayes, L., McNally, R. Rising global burden of breast cancer: the case of sub-Saharan Africa (with emphasis on Nigeria) and implications for regional development: a review; World Journal of Surgical Oncology (2018) 16:63 https://doi.org/10.1186/s12957-018-1345-2

2. Lindsey, A., Torre, M. S. P., Bray, F., Siegel, R. L., Lortet-Tieulent, M. S. \& Jemal A. (2015). CA: A Cancer Journal for Clinicians, 65 (2): 87-108.

3. Hyuna Sung, H, Ferlay, J., Siegel, R. L., Laversanne, M, Soerjomataram, I, Jemal, A., Bray, F. Global Cancer Statistics 2020: GLOBOCAN Estimates of Incidence and Mortality Worldwide for 36 Cancers in 185 Countries

4. Clegg-Lamptey, J. N. \& Vanderpuye, V. (2013). Current Global Developments in Breast Cancer and Management in Ghana. In Current Challenges with their Evolving Solutions in Surgical Practice in 
West Africa. Edited by Archampong E.O, Essuman, V. A., Dakubo, J.C. B \& Clegg-Lamptey, J. N. SubSaharan Publishers, Accra.

5. Ezeome, E. R. (2010). Delays in Presentation and Treatment of Breast Cancer in Enugu, Nigeria. Nigeria Journal of Clinical Practice 2010 13(3)311-316.

6. Kugbey, N., Oppong Asante, K., Meyer-Weitz, A. Depression, anxiety and quality of life among women living with breast cancer in Ghana: mediating roles of social support and religiosity. Support Care Cancer 28, 2581-2588 (2020). https://doi.org/10.1007/s00520-019-05027-1

7. Bailey, L. (2010). Strategies for Decreasing Patient Anxiety in the Perioperative Setting. Association of Perioperative Registered Nurses Journal, 92 (2010): 445-457.

8. Pritchard, M. J. Identifying and Assessing Anxiety in Pre-operative Patients. Nursing Standard, 23(51): 35-40, 2009.

9. Katz, S. J. \& Hawley, S. T. (2005). From Policy to Patients and Back: Surgical Treatment Decision Making for Patients with Breast Cancer. Health Affairs, 26: 761-769.

10. Braun, V. \& Clarke, V. (2006) Using Thematic Analysis in Psychology. Qualitative Research in Psychology, 3 (2): 77-101.

11. Danquah, S. A. (2008). The Relevance of African Belief System and The Patient's Choice of Treatment from the Existing Health Models in Ghana. The Mind, 1: 11-27.

12. Mbiti, J. (1990). African Religions and Philosophy. (2nd Ed.) Heinemann Educational Books Inc, England, Clays Ltd, St Ives Plc.

13. Parkinson, M. R. (2011). Established and Suspected Risk Factors for Breast Cancer: A Case-Control Study. In Vancouver, B. C \& Kingston. Master's Thesis, Department of Community Health and Epidemiology, Queen's University Kingston, Ontario, Canada.

14. Clegg-Lamptey, J. N. A, Dakubo, J. C. B. \& Attobra Y. N. (2009). Psychosocial Aspects of Breast Cancer Treatment in Accra, Ghana. East African Medical Journal, 86(7): 348-353.

15. Fang, S. Y., Shu, B. C. \& Fetzer, S. J. (2011). Deliberating Over Mastectomy: Survival and Social Roles. Cancer Nursing, 34(2), 21-28.

16. Keitel, M. A. \& Kopala, M. (2000). Counselling Women with Breast Cancer: A Guide for Professionals. Thousand Oaks, CA: Sage.

17. Sheldon, P. (2010). Pressure to be perfect: Influences on College Students' Body Esteem. Southern Communication Journal, 75(3), 277-298.

18. Howard, D. T. (2014). Skin Deep: Body Image and Interpersonal Relationship Quality in College Women. Journal of Interdisciplinary Undergraduate Research, 6(5):1-25.

19. Watson, M., Homewood, J., Haviland, J. \& Bliss, J. (2005). Influence of Psychological Response on Breast Cancer Survival: 10 Year Follow Up of a Population Based Cohort. European Journal of Cancer, 41: 1710-1714.

20. Chou, F. A., Stewart, L. S., Wild, C. R. \& Bloom, R. J. Social Support and Survival in Young Women with Breast Carcinoma. Psychooncology, 21(2):125-133, 2012. 
21. Spiegel, D. \& Kimerling, R. (2001). Group Psychotherapy for Women with Breast Cancer: Relationship among Social Support, Emotional Expression and Survival. In: C. D. Ryff \& B. H. Singer (Ed). Emotion, Social Relationships, and Health. Oxford: University Press, 97-123. 